\title{
Evidence for the association between FTO gene variants and vitamin B12 concentrations in an Asian Indian population
}

Shelini Surendran ${ }^{1}$, Ramamoorthy Jayashri ${ }^{2}$, Lauren Drysdale ${ }^{3}$, Dhanasekaran Bodhini $^{4}$, Nagarajan Lakshmipriya $^{5}$, Coimbatore Subramanian Shanthi Rani ${ }^{6}$, Vasudevan Sudha ${ }^{5}$, Julie A. Lovegrove', Ranjit M. Anjana², Viswanathan Mohan ${ }^{2}$, Venkatesan Radha ${ }^{4}$, Rajendra Pradeepa ${ }^{2}$ and Karani S. Vimaleswaran ${ }^{1 *}$

\begin{abstract}
Background: Low vitamin B12 concentrations have been associated with major clinical outcomes, including adiposity, in Indian populations. The Fat mass and obesity-associated gene (FTO) is an established obesity-susceptibility locus; however, it remains unknown whether it influences vitamin B12 status. Hence, we investigated the association of two previously studied FTO polymorphisms with vitamin B12 concentrations and metabolic disease-related outcomes and examined whether these associations were modified by dietary factors and physical activity.

Methods: A total of 176 individuals with type 2 diabetes, 152 with pre-diabetes, and 220 normal glucose-tolerant individuals were randomly selected from the Chennai Urban Rural Epidemiology Study. Anthropometric, clinical, and biochemical investigations, which included body mass index (BMI), waist circumference, vitamin B12, homocysteine, and folic acid were measured. A validated food frequency questionnaire was used for dietary assessment and selfreported physical activity measures were collected. An unweighted genetic risk score (GRS) was calculated for two FTO single-nucleotide polymorphisms (rs8050136 and rs2388405) by summation of the number of risk alleles for obesity. Interaction analyses were performed by including the interaction terms in the regression model.

Results: The GRS was significantly associated with increased BMI $(P=0.009)$ and risk of obesity $(P=0.023)$. Individuals carrying more than one risk allele for the GRS had 13.13\% lower vitamin B12 concentrations, compared to individuals carrying zero risk alleles $(P=0.018)$. No associations between the GRS and folic acid and homocysteine concentrations were observed. Furthermore, no statistically significant GRS-diet or GRS-physical activity interactions with vitamin B12, folic acid, homocysteine or metabolic-disease outcomes were observed.

Conclusion: The study shows for the first time that a genetic risk score using two FTO SNPs is associated with lower vitamin B12 concentrations; however, we did not identify any evidence for the influence of lifestyle factors on this association. Further replication studies in larger cohorts are warranted to investigate the association between the GRS and vitamin B12 concentrations.
\end{abstract}

Keywords: SNP, Obesity, Metabolic traits, Vitamin B12 pathway, South Asian, Indian, Nutrigenetics

\footnotetext{
* Correspondence: v.karani@reading.ac.uk

${ }^{1}$ Hugh Sinclair Unit of Human Nutrition and Institute for Cardiovascular and

Metabolic Research (ICMR), Department of Food and Nutritional Sciences,

University of Reading, Whiteknights, PO Box 226, Reading RG6 6AP, UK

Full list of author information is available at the end of the article
}

(c) The Author(s). 2019 Open Access This article is distributed under the terms of the Creative Commons Attribution 4.0 International License (http://creativecommons.org/licenses/by/4.0/), which permits unrestricted use, distribution, and reproduction in any medium, provided you give appropriate credit to the original author(s) and the source, provide a link to the Creative Commons license, and indicate if changes were made. The Creative Commons Public Domain Dedication waiver (http://creativecommons.org/publicdomain/zero/1.0/) applies to the data made available in this article, unless otherwise stated. 


\section{Introduction}

Obesity and its related comorbidities are leading causes of mortality and morbidity worldwide [1]. It is estimated that $>12 \%$ of the Indian population is either overweight or obese [2]. Epidemiological studies have documented that the increased accessibility of low-cost, high-calorie, and nutrient-poor foods was among the major driving forces for the epidemic of obesity [3-5]. This has led to a substantial increase in the prevalence of obesityassociated metabolic problems, such as type 2 diabetes mellitus (T2DM), dyslipidemia, and hypertension in India [6]. Furthermore, several studies have also demonstrated that obesity is associated with substantial nutrient deficiencies, including vitamin B12 [7-9].

Vitamin B12 deficiency is a major public health problem in India and a recent cross-sectional study conducted in 630 healthy adults in a South Indian population, reported that $35 \%$ of adults were vitamin B12 deficient [10]. An adequate vitamin B12 concentration is essential for growth, development, and health. In addition, it is essential for DNA synthesis, hematological development, and maintenance of the myelin nerve sheaths [11-13]. The primary causes of vitamin B12 deficiency are age, consumption of vegetarian diets, and the inability to absorb vitamin B12 from food (via genetic defects or disease) [14, 15]. To date, several studies have indicated that vitamin B12 status may be influenced by excess body weight $[16,17]$. However, a recent pooled analysis of 19 studies found no evidence for an inverse relationship between vitamin B12 and BMI levels and reported that the majority of observational studies had a high risk of bias and heterogeneity due to the fact that most of the studies were not designed to investigate the association between B12 level and BMI [18]. In light of these findings, using a genetic approach to explain the genetic mechanisms for obesity and its link with vitamin B12 concentrations could be a better option, in terms of reducing any influence from unmeasured confounding factors.

Genome-wide association studies have identified several genetic variants related to obesity and type 2 diabetes risk $[19,20]$. To date, the fat mass and obesity-associated (FTO) gene has been identified as the strongest common genetic predictor of obesity [21]. Individuals who are homozygous for FTO risk alleles are on average at 1.67-fold increased odds of obesity and $3 \mathrm{~kg}$ heavier in comparison to individuals without any risk alleles [22]. While several studies have reported the association between the FTO gene on measures of body weight and composition, various dietary parameters and physical activity levels have also been shown to contribute [23-25]. Recently, a cross-sectional study in an Indian population showed that physical activity and dietary intake may modify the association between the FTO gene variants and obesity-related traits [26]. We used FTO gene variants as instruments to establish the relationship between obesity and B12 status and tested whether this relationship was modified by lifestyle factors. The two main objectives of this study were first to determine whether the FTO single-nucleotide polymorphisms (SNPs), rs8050136, and rs2388405, were associated with obesity traits, vitamin B12, folic acid, and homocysteine and secondly whether these associations were modified by diet and physical activity levels in Asian Indians.

\section{Methodology \\ Study population}

A total of 548 unrelated study subjects were randomly recruited from the Chennai Urban Rural Epidemiology Study (CURES) follow-up study, which is an epidemiological study conducted on a representative population of Chennai, (formerly Madras) in southern India. The methodology of the study is published elsewhere $[27,28]$ and is briefly outlined here (Fig. 1). In phase 1 of CURES, 26,001 (aged $\geq 20$ years) individuals were recruited based on a systematic random sampling technique. In the baseline survey, of the 26,001 individuals screened, all the individuals with diabetes (phase $2, n=1382$ ) and 1 in every 10 individuals (phase $3, n=2207$ ) underwent further detailed investigations, and these constituted the cohort for the follow-up study $(n=3589)$. From these 3589 individuals, 548 individuals, which included: 220 NGT, 152 prediabetic, and 176 T2DM individuals were randomly selected for this study. Individuals were excluded from participation if they were known cases of type 1 diabetes, had diabetes secondary to other causes, e.g., chronic pancreatitis, if they were 80 years of age, or were taking vitamin B12 supplements. Table 1 shows the characteristics of the study participants.

The Madras Diabetes Research Foundation Institutional Ethics Committee granted ethical approval, and informed consent was obtained from the study participants. All clinical investigations were conducted according to the principles expressed in the Declaration of Helsinki (ICH GCP).

\section{Phenotype measurements}

Anthropometric measurements including weight, height, and waist circumference were measured using standardized techniques. The body mass index (BMI) was calculated using the formula, weight $(\mathrm{kg}) /$ height $\left(\mathrm{m}^{2}\right)$, and obesity was classified as $\mathrm{BMI} \geq 25$ according to WHO Asia Pacific Guidelines for Asians (The Asia Pacific perspective 2000). Fasting plasma glucose (glucose oxidase-peroxidase method) was measured using Hitachi-912 Autoanalyser (Hitachi, Mannheim, Germany). Glycated hemoglobin (HbA1c) was estimated by high-performance liquid chromatography using a Variant ${ }^{\mathrm{TM}}$ machine (Bio-Rad, Hercules, CA, USA). Serum insulin, serum vitamin $B_{12}$, and folic acid concentration were estimated using the electrochemiluminescence using a Roche e601Cobas immunoassay analyzer (Roche Diagnostics, Indianapolis, IN, USA). The intra- and 


\section{CHENNAI URBAN RURAL EPIDEMIOLOGICAL STUDY (CURES FOLLOW UP STUDY)}

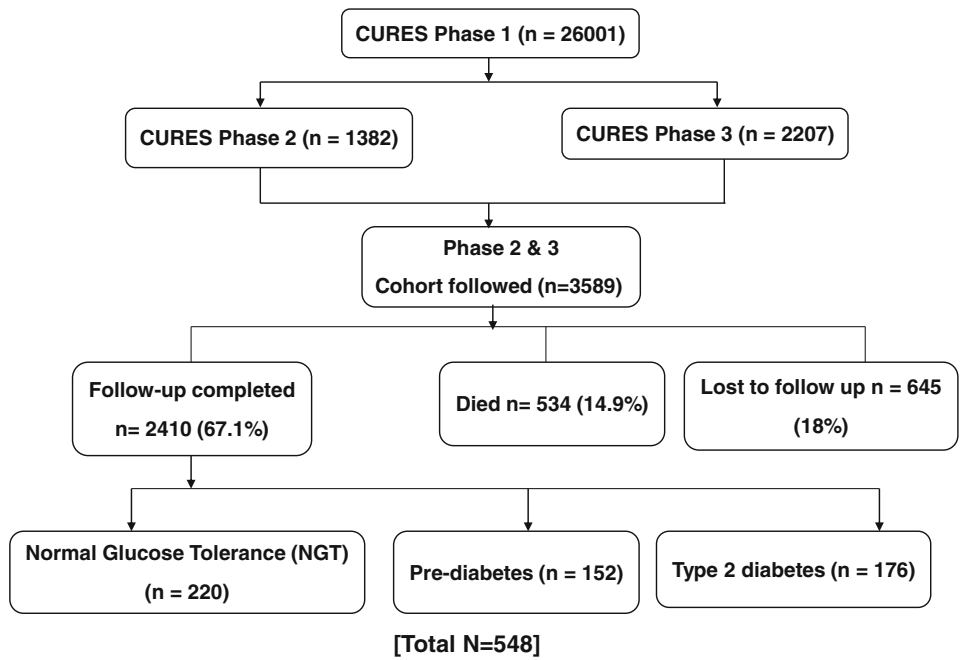

Fig. 1 Flow diagram describing the selection of study participants

Table 1 Baseline characteristics of the CURES study participants: comparison of non-obese and obese individuals

\begin{tabular}{|c|c|c|c|c|c|}
\hline Characteristic & $n$ & Non-obese individuals & $n$ & Obese individuals & $P$ value $^{*}$ \\
\hline Age (years) & 194 & $51.0 \pm 12.8$ & 353 & $48.4 \pm 10.4$ & 0.017 \\
\hline $\mathrm{BMI}\left(\mathrm{kg} / \mathrm{m}^{2}\right)$ & 194 & $21.9 \pm 2.1$ & 353 & $29.4 \pm 4.1$ & $<0.001$ \\
\hline WC (cm) & 194 & $79.7 \pm 8.1$ & 352 & $93.0 \pm 9.9$ & $<0.001$ \\
\hline Hip (cm) & 194 & $89.1 \pm 6.1$ & 352 & $102.4 \pm 9.4$ & $<0.001$ \\
\hline WHR & 194 & $0.90 \pm 0.08$ & 352 & $0.91 \pm 0.08$ & 0.061 \\
\hline Fasting plasma glucose (mg/dl) & 184 & $119.5 \pm 60.3$ & 335 & $114.7 \pm 41.6$ & 0.336 \\
\hline Fasting serum insulin ( $\mu \mathrm{l} \mathrm{U} / \mathrm{ml})$ & 194 & $8.75 \pm 6.36$ & 353 & $9.57 \pm 5.92$ & 0.132 \\
\hline Glycated hemoglobin (\%) & 194 & $6.5 \pm 1.9$ & 353 & $6.5 \pm 1.6$ & 0.916 \\
\hline Vitamin B12 levels (pg/mL) & 194 & $414.0 \pm 219.0$ & 353 & $420.0 \pm 273.0$ & 0.820 \\
\hline Homocysteine & 194 & $14.1 \pm 8.2$ & 353 & $13.4 \pm 8.0$ & 0.343 \\
\hline \multicolumn{6}{|l|}{$(\mu \mathrm{mol} / \mathrm{L})$} \\
\hline Folic acid & 194 & $8.9 \pm 5.6$ & 353 & $8.5 \pm 5.9$ & 0.451 \\
\hline \multicolumn{6}{|l|}{$(\mathrm{ng} / \mathrm{ml})$} \\
\hline Total energy intake (kcal) & 129 & $2547.0 \pm 784.0$ & 234 & $2624.0 \pm 768.0$ & 0.363 \\
\hline Protein energy \% & 129 & $11.3 \pm 1.2$ & 234 & $11.3 \pm 1.1$ & 0.947 \\
\hline Carbohydrate energy \% & 129 & $63.3 \pm 6.7$ & 234 & $64.9 \pm 6.0$ & 0.020 \\
\hline Fat energy \% & 129 & $24.2 \pm 4.6$ & 234 & $23.6 \pm 4.8$ & 0.293 \\
\hline Total fiber (g) & 129 & $31.6 \pm 10.2$ & 234 & $32.5 \pm 11.9$ & 0.513 \\
\hline \multirow[t]{3}{*}{ Physical activity level } & 123 & Low (81.3\%) & 204 & Low (82.4\%) & $0.929^{a}$ \\
\hline & & Medium (17.1\%) & & Medium (15.7\%) & \\
\hline & & High (1.6\%) & & High (2.0\%) & \\
\hline
\end{tabular}

Data shown are represented as means \pm SD

$P$ values were calculated by using the Independent $t$ test

* $P$ values for the differences in the means/proportions between non-obese and obese individuals

${ }^{a} P$ values were calculated by using the chi-squared test

Abbreviations: CURES Chennai Urban Rural Epidemiological Study; BMI body mass index; WC waist circumference; WHR waist to hip ratio 
inter-assay coefficients of variation for vitamin $B_{12}$ assay were $0.95 \%$ and $4.08 \%$. Serum homocysteine was measured using enzymatic assay using the Beckman Coulter AU2700 (Fullerton, CA, USA) Biochemistry analyzer.

\section{Dietary assessments and physical activity}

Dietary intakes were assessed using a previously validated and published interviewer-administered semiquantitative food frequency questionnaire (FFQ) containing 222 food items to estimate food intake over the past year. The length of the interview ranged from 20 and $30 \mathrm{~min}$ during which participants were asked to recall their usual portion size and usual frequency (number of times per day, week, month, or year/never) of foods listed within the FFQ over the year. Common household measures such as household cups, bowls, ladles, spoons (for the cooked foods like vegetables), wedges, circles of different diameter and visual atlas of different sizes of fruits (small, medium, large) were shown to assist the individuals in estimating portions. A detailed description of the development of FFQ and the data on reproducibility and validity had been published previously [29]. The recorded data was analyzed with the EpiNu ${ }^{\bullet}$ software to estimate energy as well as macronutrient and dietary fiber intake.

A validated self-report questionnaire was used to measure physical activity questionnaire [30]. Based on exercise, leisure time activities, and job-related activities, respondents were categorized into three groups indicating activity level (vigorously active, moderately active, and sedentary). Individuals were graded as vigorously active if they did leisure-time exercise and had physically demanding work, whereas individuals who either exercised or had physically demanding work were categorized as moderately active. All others were categorized as sedentary.

\section{SNP selection and genotyping}

Genetic variants within the FTO gene have shown consistent and strong associations with obesity [21]. Evidence suggests that the FTO gene confers an increased risk of obesity by approximately 1.20 -fold, and a corresponding increase in BMI by $0.39 \mathrm{~kg} / \mathrm{m}^{2}$ per minor allele [31]. The BMI-increasing allele in the FTO gene is less prevalent in Asian $(\sim 30 \%)$ and African populations $(\sim 12 \%)$ than in European ancestry populations $(\sim 42 \%)$. However, the effect of the risk alleles on BMI variance is somewhat similar in the Asian (0.2\%), African (0.1\%) and European populations $(0.3 \%)$ [31-33].

Of particular interest are intronic SNPs, which may harbor 'intronic enhancers' that may exert functional effects and contain potential transcriptional factor binding sites. Furthermore, some of these intronic variants have been shown to increase disease risk or modulate the genotype-phenotype relationship [34]. The SNP rs8050136 of the FTO gene has shown consistent and strong associations with obesity and type 2 diabetes [21]. Additionally, the SNP rs2388405 was previously selected for analysis in a case-control study conducted in a Chinese population, due to its possibility of being an intronic enhancer' [35] and also in a study in a Han Chinese population [36] and a Caucasian population [37]. Hence, we selected these two intronic SNPs of the FTO gene with a known minor allele frequency (MAF) $>15 \%$ in the South Asian population: rs8050136 (intron 1, MAF $=29 \%$; HapMap South Asian population) and rs2388405 (intron 4, MAF $=40 \%$; HapMap South Asian population).

The standard Phenol-chloroform method was used to extract DNA from whole blood [38]. The SNPs rs8050136 and rs2388405 were genotyped by polymerase chain reaction on a GeneAmp PCR system 9700 thermal cycler (Applied Biosystems, Foster City, CA) using the primers "F: 5'TTT GTT TTG GCT TTC TGC AGT CT3', R: CAA AAA CCA CAG GCT CAG A3' and F: 5'TCT GTG GGA ATC TCC GCT TTC AGT, R: 5' GAG CCC TTG CGC ATT GCC AG3' respectively. The PCR products were digested with MluCI (rs8050136) and ScaI (rs2388405) restriction enzymes (New England Biolabs, Inc., Beverly, MA) and the digested products were resolved by a $3 \%$ agarose gel electrophoresis. Based on the analysis of 200 blind duplicates (20\%), there was 100\% concordance in the genotyping. Furthermore, a few variants were confirmed by direct sequencing with an $\mathrm{ABI}$ 310 genetic analyzer (Foster City, CA).

\section{Statistical analysis}

The SPSS statistical package (version 22; SPSS Inc., Chicago, IL, USA) was used for the statistical analysis. Allele frequencies were estimated by gene counting. The chi-square test was used to compare the proportions of genotypes or alleles. The genotypic frequencies in all participants showed no significant departure from the Hardy Weinberg Equilibrium (HWE) $(P>0.05)$ for the FTO rs8050136 (MAF 0.13 and HWE $P=0.749$ ) and rs2388405 (MAF 0.09 and HWE $P=0.259$ ) SNPs.

Generalized obesity was defined according to the World Health Organization Asia Pacific Guidelines for Asians as non-obese $\left(\mathrm{BMI}<25 \mathrm{~kg} / \mathrm{m}^{2}\right)$ and obese $\left(\mathrm{BMI} \geq 25 \mathrm{~kg} / \mathrm{m}^{2}\right)$ [39]. We performed an independent $t$ test to compare the means of the quantitative variables between individuals with normal-glucose tolerance (NGT) vs pre-diabetes and NGT vs T2D). Comparison of the proportion of individuals engaging in different types of physical activity levels (vigorously active, moderately active, and sedentary) between NGT individuals vs pre-diabetes and NGT individuals vs T2D was analyzed by the chi-square test. 
The unweighted, risk-allele GRS method was calculated for each participant by summation of the number of risk alleles for obesity. The GRS was generated from the SNPs rs8050136 and rs 2388405 of the FTO gene. A value of 0,1 , or 2 was assigned to each SNP, which denotes the number of risk alleles for obesity on that SNP. These values were then calculated by adding the number of risk alleles across each SNP. The risk allele score was then divided into individuals carrying 0 risk allele vs more than 1 risk alleles. Association analyses between the GRS and continuous and categorical variables were carried out by linear and logistic regression models, respectively. Linear and logistic regression models were also used for interaction analyses between GRS and dietary factors (continuous variables)/physical activity (categorical variable) on continuous and categorical outcomes respectively, where the interaction terms were included in the models and were adjusted for age, BMI, sex, T2D, T2D medication, and total energy intake when appropriate.

Correction for multiple testing was applied using Bonferroni correction [adjustment $P$ value for association analysis was $<0.0083$ [ 1 GRS $\times 6$ biochemical and metabolic traits (vitamin B12, Homocysteine, folic acid, obesity, BMI, waist circumference) $=6$ tests) $]$ and for interaction $<0.0017$ [1 GRS $\times 6$ biochemical and metabolic traits $\times 5$ lifestyle factors (dietary carbohydrate energy \%, dietary protein-energy $\%$, dietary fat energy \%, dietary fiber intake (g), and physical activity levels) $=30$ tests]. Given that there are no studies on GRS and no previously reported effect sizes for the South Asians, we were unable to perform a power calculation for the present study.

\section{Results}

\section{Characteristics of the participants}

The clinical and biochemical characteristics of the individuals from the CURES study are illustrated in Table 1. No significant difference between obese and non-obese individuals were observed in the levels of fasting glucose, insulin, HbA1c, folic acid, homocysteine, vitamin $\mathrm{B} 12$ and waist to hip ratio $(\mathrm{P}>0.05)$. However we observed that obese individuals consumed higher quantities of dietary carbohydrate (energy \%) than non-obese individuals $(P=0.020)$. The baseline characteristics which compares individuals with NGT, pre-diabetes, and T2D is shown in Additional file 1: Table S1.

\section{Association of B12 level with prediabetes and type 2 diabetes}

After adjusting for age, sex, and BMI, there was no association of vitamin B12 level with prediabetes $(P=0.19)$ and type 2 diabetes $(P=0.52)$. Likewise, there was no association of vitamin B12 level with prediabetes $(P=0.22)$ and type 2 diabetes $(P=0.57)$ after adjusting for age, sex, and GRS (as an instrument for BMI).

Association between GRS and obesity-related phenotypes We were able to identify an association between GRS and BMI $(P=0.009)$. Individuals who carried more than one risk allele had higher BMI levels (mean $\pm \mathrm{SD}$ : $27.55 \pm 4.98)$ compared to individuals with zero risk alleles (mean \pm SD: $26.43 \pm 5.03$ ) (Table 2 and Fig. 2).

Obesity risk-increasing alleles ranged from 0 to 3 . The white bars indicate individuals with 0 risk alleles and the black bars indicate individuals carrying $\geq 1$ alleles. Individuals who carried 1 or more risk alleles had significantly higher BMI compared to individuals carrying 0 risk alleles $(P=0.009)]$

There was a significant association between the GRS and obesity $\left(P_{\text {association }}=0.023\right)$, where individuals carrying more than one risk allele had 1.6 times increased risk of obesity compared to those carrying zero risk alleles (Table 2). However, after Bonferroni correction, none of these associations remained statistically significant. Moreover, no statistically significant associations were observed between GRS and waist circumference $(P=0.747)$ (Table 2$)$.

Table 2 Association between the FTO-GRS with vitamin B12, folic acid, homocysteine, and obesity traits

\begin{tabular}{|c|c|c|c|c|c|c|c|c|c|c|c|c|}
\hline Risk alleles & $n$ & $\begin{array}{l}\text { Vitamin B12 } \\
(\mathrm{pg} / \mathrm{mL})\end{array}$ & $n$ & $\begin{array}{l}\text { Homocysteine } \\
(\mu \mathrm{mol} / \mathrm{L})\end{array}$ & $n$ & $\begin{array}{l}\text { Folic acid } \\
\text { (ng/ml) }\end{array}$ & $n$ & $\begin{array}{l}\mathrm{BMl} \\
\left(\mathrm{kg} / \mathrm{m}^{2}\right)\end{array}$ & $n$ & $\begin{array}{l}\text { WC } \\
(\mathrm{cm})\end{array}$ & $n$ & $\begin{array}{l}\text { Odds Ratio } \\
(95 \% \text { Cl) } \\
\text { of Obesity }\end{array}$ \\
\hline 0 & 380 & $410 \pm 202$ & 390 & $13.2 \pm 7.7$ & 390 & $8.89 \pm 5.92$ & 390 & $26.4 \pm 5.0$ & 390 & $87.6 \pm 11.1$ & 194 & $1.63(1.07-2.49)$ \\
\hline$\geq 1$ & 154 & $356 \pm 189$ & 157 & $14.8 \pm 8.9$ & 157 & $7.89 \pm 5.48$ & 157 & $27.6 \pm 5.0$ & 156 & $90.0 \pm 11.6$ & 353 & \\
\hline$P$ value & 0.018 & & 0.077 & & 0.147 & & $0.009+$ & & 0.747 & & ${ }^{*} 0.023$ & \\
\hline
\end{tabular}

Values are given as mean \pm standard deviation

$P$ values for differences between 0 and 1 risk alleles were obtained using linear regression model adjusted age, BMI, type 2 diabetes status, type 2 diabetes medication, and sex

$\dagger P$ values were obtained by using a general linear model adjusted for age, type 2 diabetes status, type 2 diabetes medication, and sex

* $P$ values were adjusted for age, sex, and type 2 diabetes status using binary logistic regression

Abbreviations: $B M I$ body mass index; WC waist circumference; WHR waist to hip ratio 


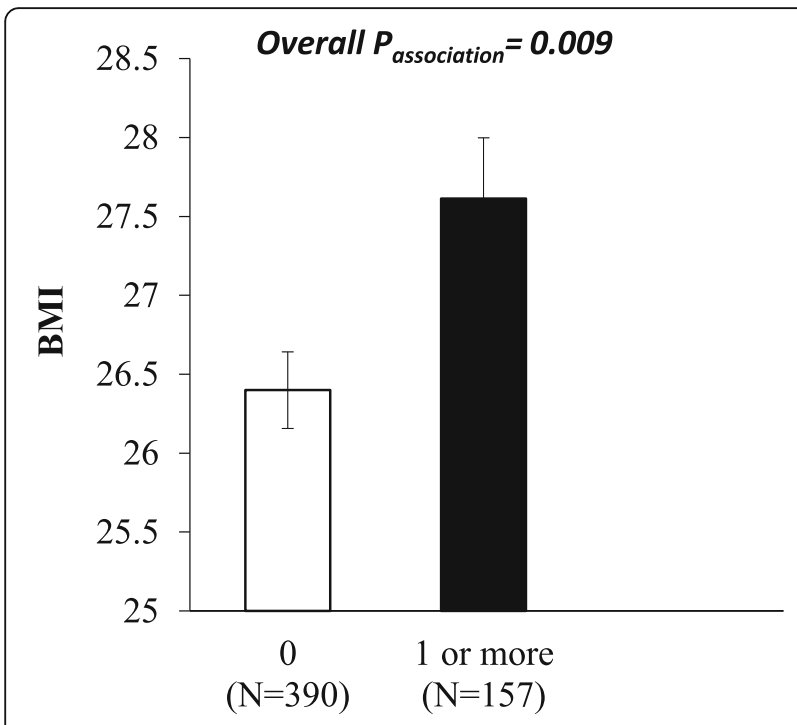

Number of metabolic disease risk alleles

Fig. 2 Association between the GRS and BMI

\section{Association between the GRS and vitamin B12, homocysteine, and folic acid levels}

We found that the GRS was significantly associated with vitamin B12 concentrations $(P=0.018)$ (Table 2 and Fig. 3), and individuals carrying more than one risk allele had 13.1\% lower vitamin B12 concentrations (mean \pm SD: $355 \pm 189 \mathrm{pg} / \mathrm{mL}$ ), compared to individuals carrying zero risk alleles (mean \pm SD: $410 \pm 202 \mathrm{pg} / \mathrm{mL}$ ). However, this finding was not significant after correction for multiple testing.

Obesity risk-increasing alleles ranged from 0 to 3 . The white bars indicate individuals with 0 risk alleles and the black bars indicate individuals carrying $\geq 1$ alleles. Individuals who carried 1 or more risk alleles had significantly

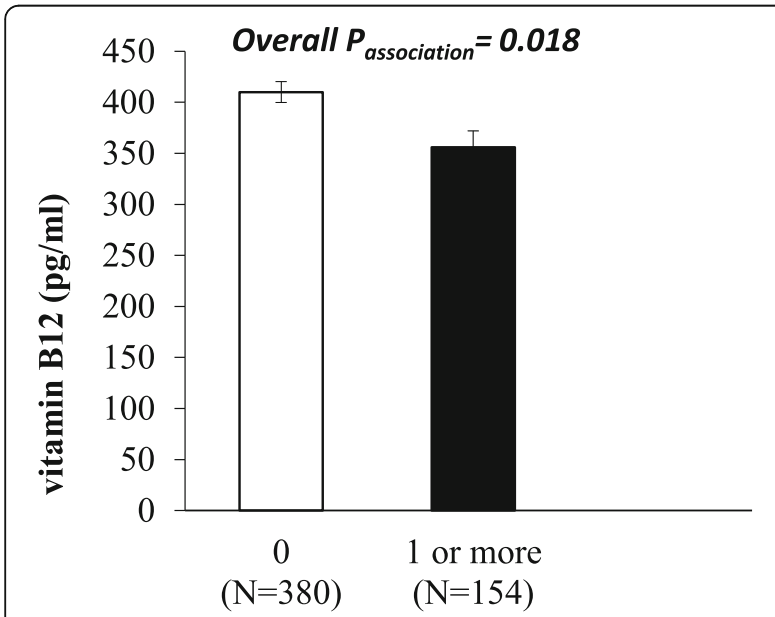

Number of metabolic disease risk alleles

Fig. 3 Association between the GRS and serum vitamin B12 levels lower B12 concentrations compared to individuals carrying 0 risk alleles $(P=0.018)$ ] (Fig. 3$)$.

There were no statistically significant associations between GRS and homocysteine or folic acid concentrations (Table 2).

\section{Interaction between the GRS and lifestyle factors on} vitamin B12, folic acid, homocysteine and obesity traits None of the lifestyle factors (dietary intake (carbohydrate, protein, fat, fiber) or physical activity) significantly interacted with the GRS on biochemical and anthropometric measurements after correction for multiple testing (Additional file 2: Table S2 and Additional file 3: Table S3).

\section{Discussion}

Both obesity and vitamin B12 deficiency are modifiable risk factors for several chronic diseases. Moreover, both risk factors have been shown previously to be associated with one another. This is the first study to use a genetic approach to establish a relationship between obesity and vitamin B12 levels in an Asian Indian population. Our study confirmed the strength of the association between the GRS generated from the two FTO SNPs and BMI and demonstrated the impact of genetically instrumented BMI on serum B12 concentrations. These results suggest that increases in BMI could potentially contribute to the adverse health effects associated with vitamin B12 deficiency. Given that low vitamin B12 concentrations in Asian Indians are common [10, 40], our study highlights the importance of considering obesity as a risk factor for vitamin B12 deficiency with implications on the possible targeting of relevant obesity prevention strategies.

Variants of the FTO gene are known to be the strongest genetic predictor of obesity to date [41, 42]. It has been suggested that risk variants at the FTO locus trigger the overexpression of ghrelin mRNA, leading to higher levels of the hunger hormone, ghrelin, to be secreted [43], which in turn makes individuals over consume energy-dense foods [44, 45]. In general, the two selected intronic SNPs rs2388405 and rs8050136 could potentially be relevant as intronic enhancers, as they may enhance the expression of the FTO gene [34]. In support of this, in a previous study conducted in a South Indian population (CURES), the FTO SNP, rs8050136, was associated with an increased risk of obesity [46]. Given the strong role of the FTO locus in obesity [21, 46], FTO was considered as a suitable candidate to establish the genetic link between obesity-related traits and vitamin B12 concentrations.

Reduced vitamin B12 concentrations in the obese population are thought to result from a nutrient-poor diet, increased nutrient requirements in relation to increased body 
size and the physiological effects of obesity on nutrient absorption/metabolism [47, 48]. Additionally, obesity is a well-known risk factor for T2DM [49] and gastroesophageal reflux disease (GERD) [50]. As a result, obese individuals are more likely to take metformin and proton pump inhibitors (PPIs), which have been shown to reduce serum B12 levels by inhibiting the absorption of the vitamin [51, 52]. However, two large Mendelian randomization studies in populations of European ancestry failed to confirm a causal relationship between low vitamin B12 concentrations and increased BMI $[53,54]$. In our study, we found a significant association of the FTO GRS (increased BMI) with low vitamin B12 concentrations in South Asian adults. Several studies in India have reported significant phenotypic associations between vitamin B12 status and obesityrelated traits $[9,16,55,56]$. A study conducted in North India reported that there was a negative correlation between waist circumference and reduced levels of vitamin B12 [55]. A study looking at 2403 schoolgoing adolescents (11-17 years) from Haryana, India reported that more than half $(51.2 \%)$ of obese adolescents were vitamin B12 deficient [9]. Furthermore, recent findings from the CURES ( $n=1500$ individuals) demonstrated that the prevalence of vitamin B12 deficiency significantly increased in those with abdominal obesity and the mean levels of vitamin B12 significantly decreased with increasing degrees of glucose tolerance [56]. However, in this study, we were unable to identify a similar trend when considering the GRS, which could be due to the smaller sample size of our study (data not shown). However, our data in Asian Indians confirms the association between vitamin B12 concentrations and obesity and suggests that individuals genetically predisposed to obesity are at a higher risk of vitamin B12 deficiency. Bi-directional Mendelian randomization studies examining the causal relationship between B12 level and obesity should be examined in Europeans and Asian Indians to identify ethnic specific differences.

Current literature suggests that the genetic profile of an individual can shape the microbiome of the host, and indeed an altered gut flora has been associated with vitamin B12 deficiency $[15,57]$. In a study in rodents, it was found that the type of dietary lipids (lard or fish oil) influenced the structure of the microbiome as there was an interaction between gut microbiota and saturated lipids in promoting white adipose tissue inflammation [58]. Chakraborty et al. postulated that a higher concentration of inflammatory cytokines could impair vitamin B12 absorption or biosynthesis [9]. Another study reported that low vitamin B12 status induced excess triacylglycerol biosynthesis and secretion of pro-inflammatory cytokines [59]. Whether the FTO genotypes influence the association between obesity and vitamin $\mathrm{B} 12$ concentrations by modulating the gut microbiota composition and inducing metabolic inflammation requires further investigation utilizing fecal samples.

The main strength of this study was the use of a validated food frequency questionnaire [60], which has shown high reproducibility and validity for total carbohydrates and dietary fiber, and the use of a GRS. Moreover, the sampling was representative of the overall population of Chennai. Nevertheless, some limitations need to be acknowledged. Although the majority of Indian adults are physically inactive and consume a diet high in carbohydrates [23, 61], no significant interactions were found between the GRS and lifestyle factors on vitamin B12 and metabolic disease outcomes in our study, which could be attributed to the small sample size. The GRS only used two variants from the FTO gene, and we cannot fully exclude that other variants of the FTO gene may also be important. Furthermore, previous studies have shown an association of B12 level with pre-diabetes and T2D [62-64]; hence, it is possible that the genetic associations identified in this study could have been mediated through the association of B12 level with diabetes. But, after adjustment for BMI, there was no significant association of B12 level with pre-diabetes and T2D suggesting the effect of GRS on B12 level in Asian Indians. Another limitation was the use of a cross-sectional design to investigate genetic effects at a single point in time and hence no causeeffect inferences can be drawn, for which a longitudinal analysis design over a specific time period would be needed.

In summary, our study, for the first time, suggests that genetic variations at the FTO locus appear to influence serum vitamin B12 concentrations in Asian Indians. However, we were unable to show an impact of the GRS on lowering B12 concentrations through a dietary influence. Longitudinal studies and large bi-directional Mendelian randomization studies could help to establish the causal relationship between vitamin B12 status and obesity in Asian Indians.

\section{Additional files}

Additional file 1: Table S1. Baseline characteristics of the CURES study participants: Comparison of NGT, Pre-diabetics and T2D individuals. (PDF $108 \mathrm{~kb}$ )

Additional file 2: Table S2. Interaction between the FTO-GRS and lifestyle factors on vitamin B12, folic acid, homocysteine and obesity traits. (PDF $96 \mathrm{~kb}$ )

Additional file 3: Table S3. Interaction between the FTO-GRS and dietary factors on obesity. (PDF $33 \mathrm{~kb}$ )

\section{Abbreviations}

BMI: Body mass index; FTO: Fat mass and obesity-associated; GRS: Genetic risk score; SD: Standard deviations; SNPS: Single-nucleotide polymorphisms; WC: Waist circumference; WHR: Waist to hip ratio 


\section{Acknowledgements}

Dr. Karani S Vimaleswaran acknowledges support from the British Nutrition Foundation. The study was supported by Lady Tata Memorial Trust, Mumbai. The Chennai Wellingdon Corporate Foundation supported the CURES field studies and this is the $152^{\text {nd }}$ paper from CURES (CURES-152).

\section{Authors' contributions}

SS and KSV drafted the paper. SS and LD performed the statistical analysis. DB carried out the genotyping analysis. KSV designed the nutrigenetics study. VM, RP, and RMA designed the CURES. VR and DB designed the genetic study. RP, NL, VS, CSS, and RJ, contributed to data collection in India. $R P, D B, J A L, N L, V S, V M, R M A$, and VR critically reviewed the manuscript. All authors read and approved the final version of the manuscript

\section{Funding}

We thank the Research Society for the Study of Diabetes in India (RSSDI) for the financial support for the study through their research grant (Project No: RSSDI/HQ/Grants/2014/250). The funders had no role in study design, data collection and analysis, decision to publish, or preparation of the manuscript.

\section{Availability of data and materials}

The datasets used during the current study are available from the corresponding author on reasonable request.

\section{Ethics approval and consent to participate}

The Madras Diabetes Research Foundation Institutional Ethics Committee granted the ethical approval and informed consent was obtained from the study participants. All clinical investigations were conducted according to the principles expressed in the Declaration of Helsinki (ICH GCP).

\section{Consent for publication}

Our manuscript does not contain any individual person's information. Informed consent was obtained from the study participants

\section{Competing interests}

The authors declare that they have no competing interests.

\section{Author details}

${ }^{1}$ Hugh Sinclair Unit of Human Nutrition and Institute for Cardiovascular and Metabolic Research (ICMR), Department of Food and Nutritional Sciences, University of Reading, Whiteknights, PO Box 226, Reading RG6 6AP, UK. ${ }^{2}$ Department of Diabetology, Madras Diabetes Research Foundation and Dr. Mohan's Diabetes Specialities Centre, WHO Collaborating Centre for Non-communicable Diseases Prevention and Control, ICMR Centre for Advanced Research on Diabetes, Gopalapuram, Chennai 600086, India. ${ }^{3}$ School of Psychology and Clinical Language Sciences, University of Reading, Reading, UK. ${ }^{4}$ Department of Molecular Genetics, Madras Diabetes Research Foundation, Chennai, India. ${ }^{5}$ Department of Foods, Nutrition and Dietetics Research, Madras Diabetes Research Foundation, Chennai, India. ${ }^{6}$ Department of Clinical Epidemiology, Madras Diabetes Research Foundation, Chennai, India.

Received: 9 May 2019 Accepted: 30 July 2019

Published online: 05 September 2019

\section{References}

1. Abdelaal M, le Roux CW, Docherty NG. Morbidity and mortality associated with obesity. Ann Translat Med. 2017;5(7):161.

2. Siddiqui MZ, Donato R. Overweight and obesity in India: policy issues from an exploratory multi-level analysis. Health Policy Plan. 2016;31(5):582-91.

3. Pappachan MJ. Increasing prevalence of lifestyle diseases: high time for action. Indian J Med Res. 2011;134(2):143-5.

4. Via M. The malnutrition of obesity: micronutrient deficiencies that promote diabetes. ISRN Endocrinol. 2012;2012:103472.

5. Forouhi NG, Misra A, Mohan V, Taylor R, Yancy W. Dietary and nutritional approaches for prevention and management of type 2 diabetes. BMJ. 2018:361:k2234-k

6. Misra A, Singhal N, Sivakumar B, Bhagat N, Jaiswal A, Khurana L. Nutrition transition in India: secular trends in dietary intake and their relationship to diet-related non-communicable diseases. J Diabetes. 2011;3(4):278-92.
7. Astrup A, Bügel S. Micronutrient deficiency in the aetiology of obesity. Int J Obes. 2010;34:947.

8. Damms-Machado A, Weser G, Bischoff SC. Micronutrient deficiency in obese subjects undergoing low calorie diet. Nutr J. 2012:11(1):34.

9. Chakraborty S, Chopra M, Mani K, Giri AK, Banerjee P, Sahni NS, et al. Prevalence of vitamin B12 deficiency in healthy Indian school-going adolescents from rural and urban localities and its relationship with various anthropometric indices: a cross-sectional study. J Hum Nutr Diet. 2018;31(4):513-22.

10. Sivaprasad M, Shalini T, Balakrishna N, Sudarshan M, Lopamudra P, Suryanarayana P, et al. Status of vitamin B12 and folate among the urban adult population in South India. Ann Nutr Metab. 2016;68(2):94-102.

11. Combs GF, McClung JP. Chapter 18 - Vitamin B12. In: Combs GF, JP MC, editors. The Vitamins (Fifth Edition): Academic Press; 2017. p. 431-52.

12. Reynolds E. Vitamin B12, folic acid, and the nervous system. Lancet Neurol. 2006;5.

13. Weir DG, Scott JM. Brain function in the elderly: role of vitamin B 12 and folate. Br Med Bull. 1999;55(3):669-82.

14. Vidal-Alaball J, Butler C, Cannings-John R, Goringe A, Hood K, McCaddon A, et al. Oral vitamin B12 versus intramuscular vitamin B12 for vitamin B12 deficiency. Cochrane Database Syst Rev. 2005:3:CD004655-CD.

15. Surendran S, Adaikalakoteswari A, Saravanan P, Shatwaan IA, Lovegrove JA, Vimaleswaran KS. An update on vitamin B12-related gene polymorphisms and B12 status. Genes Nutr. 2018;13:2.

16. Baltaci D, Kutlucan A, Turker Y, Yilmaz A, Karacam S, Deler H, et al. Association of vitamin B12 with obesity, overweight, insulin resistance and metabolic syndrome, and body fat composition; primary care-based study. Med Glas (Zenica). 2013;10(2):203-10.

17. Baltaci D, Deler MH, Turker Y, Ermis F, lliev D, Velioglu U. Evaluation of serum Vitamin B12 level and related nutritional status among apparently healthy obese female individuals. Niger J Clin Pract. 2017;20(1):99-105.

18. Wiebe N, Field CJ, Tonelli M. A systematic review of the vitamin B12, folate and homocysteine triad across body mass index. Obes Rev. 2018;19(11):1608-18.

19. Fall T, Ingelsson E. Genome-wide association studies of obesity and metabolic syndrome. Mol Cell Endocrinol. 2014;382(1):740-57.

20. Wheeler E, Barroso I. Genome-wide association studies and type 2 diabetes. Brief Funct Genomics. 2011;10(2):52-60.

21. Vimaleswaran KS, Loos RJ. Progress in the genetics of common obesity and type 2 diabetes. Expert Rev Mol Med. 2010;12:e7.

22. Frayling TM, Timpson NJ, Weedon MN, Zeggini E, Freathy RM, Lindgren $C M$, et al. A common variant in the FTO gene is associated with body mass index and predisposes to childhood and adult obesity. Science. 2007; 316(5826):889-94

23. Anjana RM, Pradeepa R, Das AK, Deepa M, Bhansali A, Joshi SR, et al. Physical activity and inactivity patterns in India-results from the ICMRINDIAB study (Phase-1) [ICMR-INDIAB-5]. Int J Behav Nutr Phys Act. 2014;11(1):26

24. Mohan V, Spiegelman D, Sudha V, Gayathri R, Hong B, Praseena K, et al. Effect of brown rice, white rice, and brown rice with legumes on blood glucose and insulin responses in overweight Asian Indians: a randomized controlled trial. Diabetes Technol Ther. 2014;16(5):317-25.

25. Merritt DC, Jamnik J, El-Sohemy A. FTO genotype, dietary protein intake, and body weight in a multiethnic population of young adults: a crosssectional study. Genes Nutr. 2018;13(1):4.

26. Vimaleswaran KS, Bodhini D, Lakshmipriya N, Ramya K, Anjana RM, Sudha V, et al. Interaction between FTO gene variants and lifestyle factors on metabolic traits in an Asian Indian population. Nutr Metab. 2016;13:39.

27. Anjana RM, Shanthi Rani CS, Deepa M, Pradeepa R, Sudha V, Divya Nair H, et al. Incidence of diabetes and prediabetes and predictors of progression among Asian Indians: 10-Year Follow-up of the Chennai Urban Rural Epidemiology Study (CURES). Diabetes Care. 2015;38(8):1441-8.

28. Deepa M, Pradeepa R, Rema M, Mohan A, Deepa R, Shanthirani S, et al. The Chennai Urban Rural Epidemiology Study (CURES)—study design and methodology (urban component) (CURES-I). J Assoc Physicians India. 2003;51:863-70

29. Sudha V, Radhika G, Sathya RM, Ganesan A, Mohan V. Reproducibility and validity of an interviewer-administered semi-quantitative food frequency questionnaire to assess dietary intake of urban adults in southern India. Int J Food Sci Nutr. 2006;57(7-8):481-93.

30. Mohan V, Gokulakrishnan K. Deepa R, Shanthirani CS, Datta M. Association of physical inactivity with components of metabolic syndrome and 
coronary artery disease - the Chennai Urban Population Study (CUPS no. 15). Diabet Med. 2005;22(9):1206-11.

31. Loos RJ, Yeo GS. The bigger picture of FTO: the first GWAS-identified obesity gene. Nat Rev Endocrinol. 2014;10(1):51-61.

32. Speliotes EK, Willer CJ, Berndt SI, Monda KL, Thorleifsson G, Jackson AU, et al. Association analyses of 249,796 individuals reveal eighteen new loci associated with body mass index. Nat Genet. 2010;42(11):937-48.

33. Li H, Kilpelainen TO, Liu C, Zhu J, Liu Y, Hu C, et al. Association of genetic variation in FTO with risk of obesity and type 2 diabetes with data from 96,551 East and South Asians. Diabetologia. 2012;55(4):981-95.

34. Cooper DN. Functional intronic polymorphisms: Buried treasure awaiting discovery within our genes. Hum Genomics. 2010;4(5):284-8.

35. Chang Y-C, Liu P-H, Lee W-J, Chang T-J, Jiang Y-D, Li H-Y, et al. Common variation in the fat mass and obesity-associated (FTO) gene confers risk of obesity and modulates BMI in the Chinese population. Diabetes. 2008;57(8):2245-52.

36. Wang $T$, Huang $Y$, Xiao XH, Wang DM, Diao CM, Zhang F, et al. The association between common genetic variation in the FTO gene and metabolic syndrome in Han Chinese. Chin Med J. 2010;123(14):1852-8.

37. Pettersen E, Skorpen F, Kvaloy K, Midthjell K, Grill V. Genetic heterogeneity in latent autoimmune diabetes is linked to various degrees of autoimmune activity: results from the Nord-Trondelag Health Study. Diabetes. 2010;59(1):302-10.

38. Sambrook J, Fritsch EF, Maniatis T, Laboratory CSH. Molecular cloning: a laboratory manual: Cold Spring Harbor Laboratory Press; 1989.

39. Committee A-PS, Zimmet P, Inoue S, Institute ID. The Asia-Pacific perspective: redefining obesity and its treatment: Health Communications Australia; 2000.

40. Yajnik CS, Deshpande SS, Lubree HG, Naik SS, Bhat DS, Uradey BS, et al. Vitamin B12 deficiency and hyperhomocysteinemia in rural and urban Indians. J Assoc Physicians India. 2006;54:775-82.

41. Bradfield JP, Taal HR, Timpson NJ, Scherag A, Lecoeur C, Warrington NM, et al. A genome-wide association meta-analysis identifies new childhood obesity loci. Nat Genet. 2012;44(5):526-31.

42. Vimaleswaran KS, Angquist L, Hansen RD, van der AD B-NN, Holst C, et al. Association between FTO variant and change in body weight and its interaction with dietary factors: the DiOGenes study. Obesity (Silver Spring, Md). 2012;20(8):1669-74.

43. Karra E, O'Daly OG, Choudhury Al, Yousseif A, Millership S, Neary MT, et al. A link between FTO, ghrelin, and impaired brain food-cue responsivity. J Clin Invest. 2013;123(8):3539-51.

44. Timpson NJ, Emmett PM, Frayling TM, Rogers I, Hattersley AT, MCCarthy MI, et al. The fat mass- and obesity-associated locus and dietary intake in children. Am J Clin Nutr. 2008;88(4):971-8.

45. Tanofsky-Kraff M, Han JC, Anandalingam K, Shomaker LB, Columbo KM, Wolkoff LE, et al. The FTO gene rs9939609 obesity-risk allele and loss of control over eating. Am J Clin Nutr. 2009;90(6):1483-8.

46. Ramya K, Radha V, Ghosh S, Majumder PP, Mohan V. Genetic variations in the FTO gene are associated with type 2 diabetes and obesity in south Indians (CURES-79). Diabetes Technol Ther. 2011;13(1):33-42.

47. Pinhas-Hamiel O, Doron-Panush N, Reichman B, Nitzan-Kaluski D, Shalitin S, Geva-Lerner L. Obese children and adolescents: a risk group for low vitamin B12 concentration. Arch Pediatr Adolesc Med. 2006;160(9):933-6.

48. MacFarlane AJ, Greene-Finestone LS, Shi Y. Vitamin B-12 and homocysteine status in a folate-replete population: results from the Canadian Health Measures Survey. Am J Clin Nutr. 2011;94(4):1079-87.

49. Al-Goblan AS, Al-Alfi MA, Khan MZ. Mechanism linking diabetes mellitus and obesity. Diabetes Metab Syndr Obes. 2014;7:587-91.

50. Chang P, Friedenberg F. Obesity \& GERD. Gastroenterol Clin N Am. 2014;43(1):161-73.

51. Wiebe N, Field CJ, Tonelli M. A systematic review of the vitamin B12, folate and homocysteine triad across body mass index. Obes Rev.

52. Miller JW. Proton pump inhibitors, H2-receptor antagonists, metformin, and vitamin B-12 deficiency: clinical implications. Adv Nutr. 2018;9(4):511s-8s.

53. Allin KH, Friedrich N, Pietzner M, Grarup N, Thuesen BH, Linneberg A, et al. Genetic determinants of serum vitamin B12 and their relation to body mass index. Eur J Epidemiol. 2016:1-10.

54. Moen GH, Qvigstad E, Birkeland KI, Evans DM, Sommer C. Are serum concentrations of vitamin B-12 causally related to cardiometabolic risk factors and disease? A Mendelian randomization study. Am J Clin Nutr. 2018;108(2):398-404.
55. Narang M, Singh M, Dange S. Serum homocysteine, vitamin B12 and folic acid levels in patients with metabolic syndrome. J Assoc Physicians India. 2016;64(7):22-6.

56. Jayashri R, Venkatesan U, Rohan M, Gokulakrishnan K, Shanthi Rani CS, Deepa M, et al. Prevalence of vitamin B12 deficiency in South Indians with different grades of glucose tolerance. Acta Diabetol. 2018;55(12):1283-93.

57. Hall $A B$, Tolonen $A C$, Xavier RJ. Human genetic variation and the gut microbiome in disease. Nat Rev Genetics. 2017;18(11):690-9.

58. Caesar R, Tremaroli V, Kovatcheva-Datchary P, Cani PD, Backhed F. Crosstalk between gut microbiota and dietary lipids aggravates WAT inflammation through TLR signaling. Cell Metab. 2015;22(4):658-68.

59. Samavat J AA, Boachie J, Zammit V, Saravanan P. Vitamin B12 deficiency triggers adipocyte dysfunction by enhancing triglyceride biosynthesis and pro-inflammatory cytokine production: a new agonist in metabolic disease? Society for Endocrinology BES 2017; Harrogate: Endocrine Abstracts 50 PL1; 2017.

60. Uma Jyothi K, Jayaraj M, Subburaj KS, Prasad KJ, Kumuda I, Lakshmi V, et al. Association of TCF7L2 gene polymorphisms with T2DM in the population of Hyderabad, India. PloS One. 2013;8(4):e60212.

61. Mohan V, Radhika G, Sathya RM, Tamil SR, Ganesan A, Sudha V. Dietary carbohydrates, glycaemic load, food groups and newly detected type 2 diabetes among urban Asian Indian population in Chennai, India (Chennai Urban Rural Epidemiology Study 59). Br J Nutr. 2009;102(10):1498-506.

62. Knight BA, Shields BM, Brook A, Hill A, Bhat DS, Hattersley AT, et al. Lower circulating B12 is associated with higher obesity and insulin resistance during pregnancy in a non-diabetic White British population. PloS One. 2015;10(8):e0135268.

63. Sukumar N, Venkataraman H, Wilson S, Goljan I, Selvamoni S, Patel V, et al. Vitamin B12 status among pregnant women in the UK and its association with obesity and gestational diabetes. Nutrients. 2016;8(12):768.

64. Adaikalakoteswari A, Vatish M, Alam MT, Ott S, Kumar S, Saravanan P. Low vitamin B12 in pregnancy is associated with adipose-derived circulating miRs targeting PPARgamma and insulin resistance. J Clin Endocrinol Metab. 2017;102(11):4200-9.

\section{Publisher's Note}

Springer Nature remains neutral with regard to jurisdictional claims in published maps and institutional affiliations.

Ready to submit your research? Choose BMC and benefit from:

- fast, convenient online submission

- thorough peer review by experienced researchers in your field

- rapid publication on acceptance

- support for research data, including large and complex data types

- gold Open Access which fosters wider collaboration and increased citations

- maximum visibility for your research: over $100 \mathrm{M}$ website views per year

At BMC, research is always in progress.

Learn more biomedcentral.com/submissions 